\title{
System Design and Implementation of Old People's Medicine Cabinet
}

\author{
Zhao Zhanfeng \\ Wenzhou Vocational \& Technical College, Wenzhou. 325035 \\ Zhanfeng@qq.com
}

Keywords: Old people, medical kit, system, implementation.

\begin{abstract}
With the obvious improvement of China's economic situation, people pay more and more attention to their heath. So we all have some medicine at home. But medicines are plentiful and messy and there are more medicines in stock than there are in stock. Besides, drugs can't be placed at random because it takes up too much space. It is better that we keep the medicine in the medicine cabinet, so the small medicine cabinet at home has become an indispensable article. This is especially true for older people who have difficulty taking care of themselves. As they get older, older people become less healthy and need more medicine every day. Besides, children cannot stay with their parents for a long time, and the elderly can only take care of themselves, and they have to take a lot of medicine every day. Therefore, the management of drugs has become a big problem.
\end{abstract}

\section{Introduction}

In the current market, there are many kinds of medicine boxes, which can be roughly divided according to the number of materials and layers. This paper studies the innovative design of the elderly medicine cabinet with the existing science and technology as the main design object.

According to part of the market survey, we have learned about the characteristics, functions and different needs of elderly people for the products on the market. We found out the problems in the design of existing products and carried out research and analysis. Through reading a large number of documents, I sorted out and analyzed the types of common diseases and medicines for the elderly, and analyzed the forms of various drugs (solid and liquid). We design according to different types of packaging storage, and highlight various structural elements in the design. Therefore, it lays a theoretical foundation for humanized design.

Study on design elements of medicine cabinet. First of all, various theoretical concepts of product design should be summarized and sorted out, so as to study the elements of such products. The design theory combines the actual needs and physiological habits of the elderly users, so as to comprehensively design the "people-oriented" products. 


\section{Problems with Existing Products in the Market}

Functional analysis: at present, the small family medicine box in the market has played a protective role in the preservation of drugs to a certain extent. However, there is no reasonable design for the elderly, and there is no in-depth research and analysis on the elderly.

Material Analysis: Most medicine cases on the market today are made of plastic or metal. Plastic material is lighter, but it is fragile. So these kind cases cannot protect some drugs that need to avoid light. Metal materials are more anti - fall but more heavy, not suitable for the elderly. Material: AbS material; Aluminum Frame, As shown in Figure 1、2.

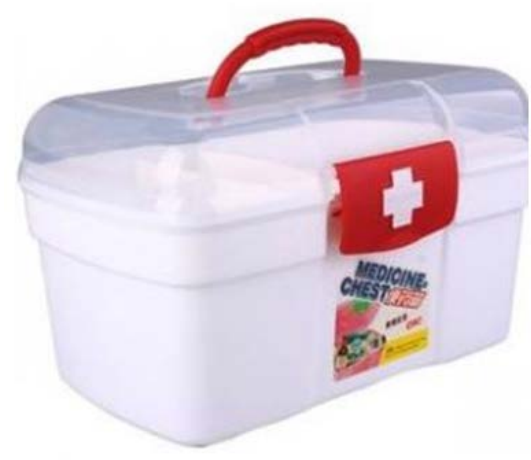

Figure 1. AbS material

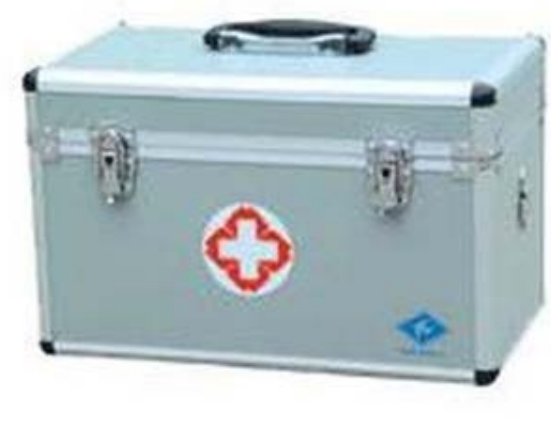

Figure 2 Aluminum Frame

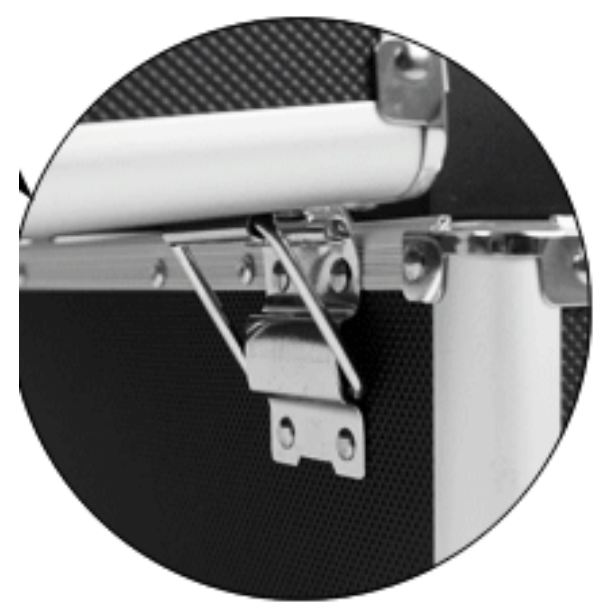

Figure 3 Supporting metal hinges

With supporting metal hinge, the cover of the box is 90 degrees after opening, making the box more stable. As shown in Figure 3. 


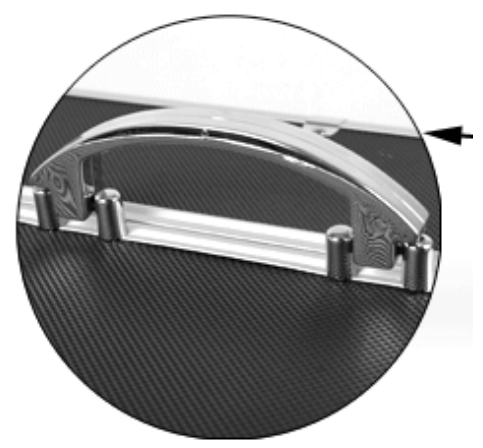

Figure 4 The handle of the box is plated with silver to make it lighter and at the same time

The handle of the box is plated with silver to make it lighter and at the same time, it also has a metallic effect. As shown in Figure 4.

\section{Inner size:}

Case handle, hardware corner, and durable, never deformed

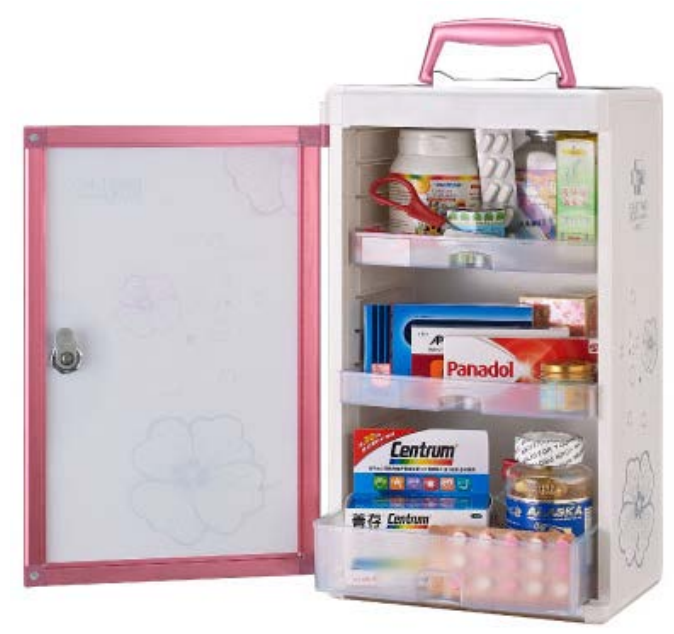

Figure 5 The analysis of the above brands

The medicine cabinet is equipped with three drawers which can be adjusted up and down. Through the analysis of the above brands, all the medicine boxes have the function of storing medicine. It has made detailed planning and classification for the structure, but there is no special design for the elderly, which is a loophole in this aspect. As shown in Figure 5.

First of all, we should start with the psychology of the elderly and focus on their living habits and psychological characteristics. The life of old people is always accompanied by medicine, so it is inevitable to put all kinds of medicine boxes at home. But these boxes make people feel not good. Because they give them the feeling that I'm sick, I'm old, and that I have to take medicine. The idea is to change the whole idea and make the box part of the home. At the same time, the product has a timing function on the surface. When used, the time for taking medicine can be set. At a certain time, voice reminder will be sent to remind the elderly that "it is time to take medicine". The upper part of the medicine cabinet can be pressed down at a certain time, and a prompt voice will be issued at the time of arrival, until the user opens the lid. Inside is space for drugs. As shown in Figure 6. 


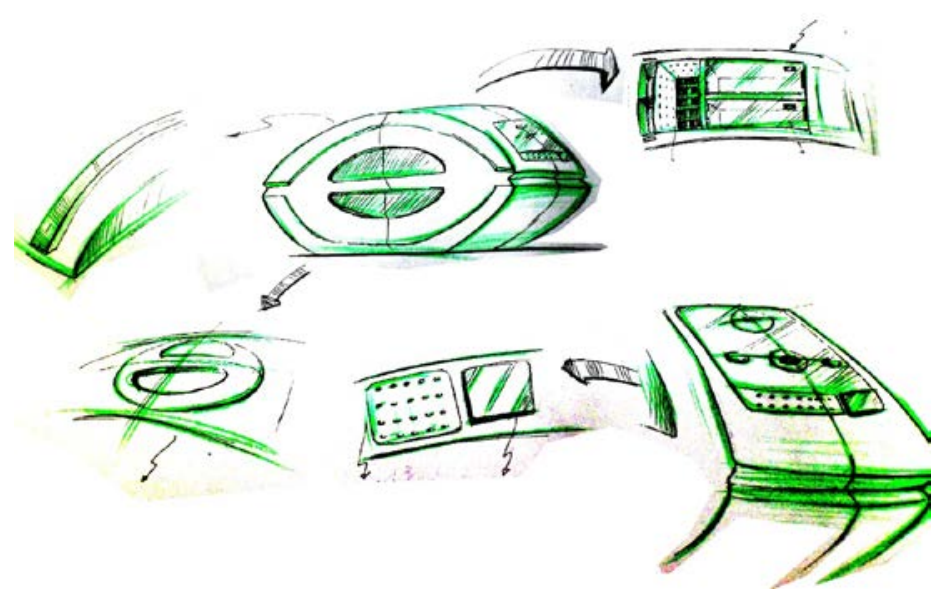

Figure 6 First of all

The middle part is the combination of the scanner and the display. There's a magnifying glass at the top, and you can take it off at any time, or you can take it off and do something else. The middle part, such as the lower left, can be switched on and off on both sides, placing small bottles of medicine or bags of medicine. The rest can be packed in large packages. As shown in Figure 7.
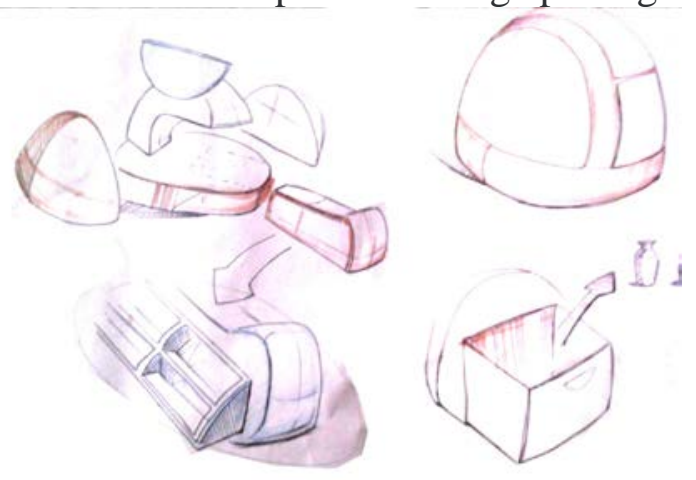

Figure 7 Sketcher

This scheme is designed mainly from the perspective of structure, combining the lamp with the medicine cabinet, giving the old people a psychological hint and a power from the modeling. It is assembled in rows to form a whole. The middle part is the combination of the scanner and the display. As people get older, their eyesight will always be poorer. If you forget the name of the medicine or don't know how to take it, you can scan the medicine and display it on the screen below. It's connected to the light in the upper part. The rest is the whole thing in the lower right corner. It can be removed from the outermost transparent membrane, and the inner structure is shown in the lower left corner, divided into several layers according to the size of the drug. As shown in Figure 8. 


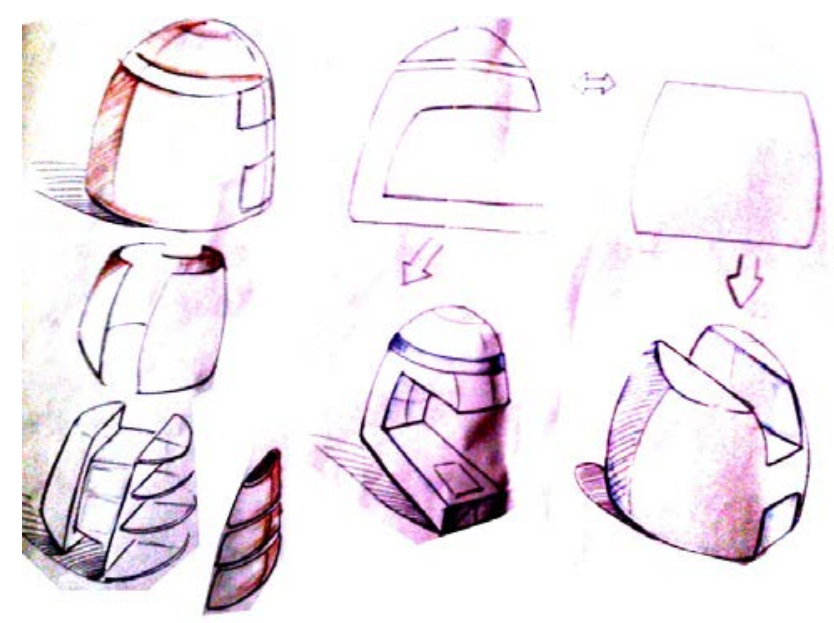

Figure 8 Sketch

\section{Innovative Point}

(1)We break the concept that the traditional medicine cabinet has a square appearance. The appearance of the medicine cabinet is designed to make the appearance of the domestic medicine cabinet more approachable, so that the use of the medicine cabinet no longer becomes a psychological burden for the elderly.

(2) We take the new technology as the most fundamental driving force. Through the innovation in the function of the medicine cabinet, we can realize the function of timing, voice prompt, scanning, subtitles and reading aloud of the medicine cabinet. Whether it is the internal structure, the connection mode or the external overall shape, we all from the biggest Angle to achieve the optimal drug placement.

(3)We change the current market for most of the medicine cabinet design on the shortcomings. Often the medicine cabinet product does not have specific classification. There is no professional medicine box for the elderly. So we hope that the new designs in this paper can meet the demand of the elder people.

(4) The color of most medicine boxes on the market is single, and most of them are made of transparent or metal materials. Therefore, the visual effect is too heavy. This design hopes to make a breakthrough in the material and color of the medicine cabinet, adopting a more bright and light color, and even realizing the change of color.

(5) On the basis of solving the above problems of the existing medicine cabinet, it is necessary to design the man-machine interface in all aspects, so as to make the display content easy to recognize and recognize, and operate concisely and conveniently.

(6) The design of medicine cabinet should apply ergonomics, and apply ergonomics to the design. This is a typical design method that first satisfies people's physical needs (comfort) and then satisfies people's psychological needs (intimacy). This paper makes a comprehensive analysis of users' usage habits, operation modes, usage environment and man-machine interaction, so as to bring the best experience to users.

(7) We adopt green design thinking in line with the principles of environmental protection, energy conservation and emission reduction, and give full consideration to the energy consumption during the production and use of household medicine boxes. And we successfully achieved green design, green production, and green recycling.

Through the early discussion and study of the elderly at home behavior and lifestyle as well as the design of the interactive relationship, I have learned the basic knowledge and market situation 
of the household medicine cabinet, and determined the following product style positioning: Make every effort to be practical on modelling, undertake structural design from practical Angle and get rid of the shape and function of the square body of the medicine box. Through existing technologies, the elderly can experience the changes brought by technology to their lives. Convenient timing function and voice prompt function solve the problem that old people always forget to take medicine. And scanning helps older people identify unfamiliar drugs. At the same time, the use of new materials, no doubt on the premise of ensuring the possibility of products, greatly reduce the total weight of products. In terms of modeling, it is designed from the perspectives of multi-function and portability. One of the top 10 principles of product design summed up by design master (Dieter Rams ) is this:"Good design creates valuable products.” The first thing to design is to make the product as practical as possible. Whether the main function or auxiliary function of the product, there must be a specific and definite purpose. Functional principles can be said to be the most basic requirements of product design, so the walker certainly is no exception. Therefore, Modeling, structure and materials are combined to achieve the personality, simplicity and portability of the product, which satisfies the special demand of the current market for the elderly medicine box. Donald Norman, a cognitive scientist, put it this way: "When a product is designed for a more relaxing and pleasant occasion, its applicability can be enhanced through a pleasant, aesthetically pleasing design.”

\section{Simplex design}

The medicine box structure design for the elderly should be simple, simple, generous, stable and stable. When designing, we should study the beauty of traditional modeling, flexibly apply and break through the tradition, and create new products with humanization. When conducting structural design, the design should conform to the different psychology of men and women. Besides, the design will be more attractive with their fresh color.

\subsection{Visualizing design}

Visual design is no longer a simple design of form and shape, but refers to the understanding, experience and evaluation of the product as a whole by the elderly and the public. The image design of the medicine cabinet is the design of the product itself. This kind of design is centering on people's need for products, which suits the individual and social needs of people to the maximum extent, and thus obtains universal recognition. Furthermore, it helps to change people's way of life, improve their living standard and quality of life. From the perspective of structural design, image mainly refers to the comprehensive appearance of products, including the internal performance, character and concept structure.

\subsection{Functional Design}

The design of the medicine cabinet is not only good-looking, but also has a great function that buyer's value. The function here is the design of the structure. The design should be used in accordance with the actual needs. Nowadays, the connotation of functional design has been extended. It also needs to meet people's spiritual needs, that is, the function of culture.

\section{Conclusion}

Shared design is a concept in ergonomics, which is the highest development of the "people-oriented" design concept. Common design was first used in barrier-free design and is now 
used in all areas of design. he significance of its design philosophy lies in protecting the interests of the vulnerable groups and showing the care for the vulnerable groups. In addition, the design mode that originally separated the design of this part of the population from that of normal people was changed. There are two aspects in the design of medicine cabinet: The first is how this product can make up for the different user experience of different elderly groups. The other is how to make products to meet the psychological value of the elderly consumers. Shared design involves ergonomics, anthropometry, biomechanics, psychology, etc. A large amount of data experimental data is required in the design. It requires products to be designed and produced in accordance with the principle of fairness, that is, any group can benefit from the products. And it also can be used skillfully and flexibly, take care of different users' different habits and abilities. Of course, no product can be perfect. So shared design is not an absolute requirement for every user. However, the design concept, which is based on the common needs of all social members, reflects the humanitarian design trend. Only with defects can there be a process of design.

\section{References}

[1]Chia-Lin Hsu,Yen-Chun Chen,Tai-Ning Yang,Wei-Ko Lin,Yi-Hsuan Liu. Does product design matter? Exploring its influences in consumers' psychological responses and brand loyalty[J]. Information Technology \& People,2018,31(3).

[2]Asmae Abadi,Hussain Ben-Azza,Souhail Sekkat. Improving integrated product design using SWRL rules expression and ontology-based reasoning[J]. Procedia Computer Science,2018,127.

[3]Luis J. Zeballos,Carlos A. Méndez,Ana P. Barbosa-Povoa. Integrating decisions of product and closed-loop supply chain design under uncertain return flows[J]. Computers and Chemical Engineering,2018,112.

[4]Bin He,Jinglong Xiao,Zhongqiang Deng. Product design evaluation for product environmental footprint[J]. Journal of Cleaner Production,2018,172.

[5]Dimitris Mourtzis,Vasilios Zogopoulos,Ekaterini Vlachou. Augmented Reality supported Product Design towards Industry 4.0: a Teaching Factory paradigm[J]. Procedia Manufacturing,2018,23.

[6]S.M. Ibbotson,S. Kara. A Framework for Determining the Life Time Energy Consumption of a Product at the Concept Design Stage[J]. Procedia CIRP,2018,69.

[7]Bryndis Stefansdottir,Martin Grunow. Selecting new product designs and processing technologies under uncertainty: Two-stage stochastic model and application to a food supply chain[J]. International Journal of Production Economics,2018,201.

[8]S M Ibbotson,S Kara. An approach to identify the factors that affect a products life time energy consumption during the concept design stage[J]. Procedia CIRP,2018,70.

[9]Philipp Savarino,Michael Abramovici,Jens Christian Göbel,Philip Gebus. Design for reconfiguration as fundamental aspect of smart products[J]. Procedia CIRP,2018,70.

[10]Miguel González-Maestre,Lluís M. Granero. Competition with targeted product design: Price, variety, and welfare [J]. International Journal of Industrial Organization,2018,59.

[11]Shamraiz Ahmad,Kuan Yew Wong,Ming Lang Tseng, Wai Peng Wong. Sustainable product design and development: A review of tools, applications and research prospects[J]. Resources, Conservation \& Recycling,2018,132.

[12]Jing Li,Yafei Nie,Xinwei Zhang,Keqin Wang,Shurong Tong,Benoît Eynard. A Framework Method of User-participation Configuration Design for Complex Products[J]. Procedia CIRP,2018,70.

[13]Mary Kathryn Thompson,Ida Kirstine Juel Jespersen,Thomas Kjærgaard. Design for manufacturing and assembly key performance indicators to support high-speed product development[J]. Procedia CIRP,2018,70.

[14]Ivonne Rodriguez-Donis,Sophie Thiebaud-Roux,Sophie Lavoine,Vincent Gerbaud. Computer-aided product design of alternative solvents based on phase equilibrium synergism in mixtures[J]. Comptes rendus - Chimie,2018,21(6).

[15]Daniel W. Steeneck,Subhash C. Sarin. Product design for leased products under remanufacturing[J]. International Journal of Production Economics,2018,202.

[16]Kuo-Yi Lin. User Experience-Based Product Design for Smart Production to Empower Industry 4.0 in the Glass Recycling Circular Economy[J]. Computers \& Industrial Engineering,2018.

[17]Ka Y. Fung,Ka M. Ng. Teaching chemical product design using design projects[J]. Education for Chemical Engineers,2018,24.

[18]Jessica Olivares Aguila,Waguih ElMaraghy. Simultaneous global supply chain and product architecture design considering natural hazard exposure and geographical facility location[J]. Procedia CIRP,2018,72. 